\title{
Determinação dos Coeficientes de Atrito Estático e Cinético Utilizando-se a Aquisição Automática de Dados
}

Determination of static and kinetic friction coefficients using automatic data colletction

\author{
Véra Lúcia da Fonseca Mossmann, Kelen Berra de Mello Francisco Catelli, \\ Helena Libardi e Igino Santo Damo \\ DEFQ - CCET - Universidade de Caxias do Sul, \\ Caixa Postal 1352, CEP 95001-970, Caxias do Sul-RS
}

Recebido em 25 de janeiro, 2002. Aceito em 15 de abril, 2002.

\begin{abstract}
Este trabalho descreve a informatização de um experimento tradicional envolvendo a medida de coeficientes de atrito. A montagem experimental aqui sugerida é destinada ao ensino de física a nível médio. Nela, as forças de atrito cinético e estático, para um par de superfícies, são obtidas em tempo real quando um corpo é levado do repouso ao movimento. A relação entre a força de atrito e a força normal também é apresentada. Os dados são adquiridos por um sensor de força e um sensor de posição acoplados a uma interface conectada a um computador. Os gráficos da força de atrito em função do tempo são obtidos em tempo real.
\end{abstract}

This paper describes the computer handling of a traditional experiment involving the measure of friction coefficients. The experimental setup suggested here is intended to physics teaching at high school level. The forces of kinetic and static friction, for a pair of surfaces, are obtained in real time, when a body is taken from the rest to movement. The relationship between the friction force and the normal force is also presented. The data are obtained through a force sensor and a position sensor, coupled to an interface connected to a computer. The graphics of the friction force versus time are obtained in real time.

\section{Introdução}

Desde tempos imemoráveis, os fenômenos envolvendo atrito têm atraído a atenção da humanidade: em 1508, Leonardo da Vinci, o conhecido pintor e escultor italiano, descobriu que a força de atrito entre dois corpos depende da força que comprime um contra o outro e não depende da área de contato das superfícies. G. Amontons, em 1699, redescobriu essas duas características do atrito, e acresceu-lhes uma terceira: o atrito não depende da velocidade (Da Vinci não havia dado a público seus resultados). Essas três propriedades são conhecidas como leis do atrito[1]. Como se vê, experimentos envolvendo este conceito não são em princípio novidade. Os novos recursos da informática, tanto de software como de hardware na área de aquisição de dados, permitem que a execução de experimentos antes restritos à pesquisa pura seja também estendida à sala de aula do ensino médio.

\section{Teoria}

As superfícies dos corpos, por mais polidas que possam parecer do ponto de vista macroscópico, apresentam rugosidade quando analisadas microscopicamente. Em conseqüência, se duas superfícies em contato apresentarem tendência a se mover uma em relação à outra, surge uma força "resistente": a força de atrito. No caso de a força aplicada não ser suficiente para colocar o corpo em movimento, a força de atrito se opõe à força aplicada e é chamada força de atrito estático. Esta não possui um valor único e pode variar entre zero e um certo valor máximo, chamado força de atrito estático máximo $\left(f_{e \text { máx }}\right)$. Com boa aproximação, este valor é independente da área de contato e é proporcional à força normal que a superfície exerce sobre o corpo. A constante de proporcionalidade é o "coeficiente de atrito estático" $\left(\mu_{e}\right)$. Assim, podemos escrever:

$$
f_{e} \leq f_{\text {emáx }}
$$


com

$$
f_{e \text { máx }}=\mu_{e} \cdot F_{N}
$$

No caso de ocorrer movimento, aparece a chamada força de atrito cinético $\left(f_{c}\right)$ entre as superfícies, que tem sentido contrário ao do movimento. A teoria prevê que ela seja constante, independente da área de contato e proporcional à força normal exercida por uma das superfícies sobre a outra. Esta proporcionalidade é expressa através do chamado "coeficiente de atrito cinético" $\left(\mu_{c}\right)$

$$
f_{c}=\mu_{c} \cdot F_{N}
$$

As constantes de atrito estático e cinético podem dizer muito sobre as características das superfícies em contato. É interessante destacar que o coeficiente de atrito estático máximo é sempre maior que o coeficiente de atrito cinético $\left(\mu_{e \text { más }}>\mu_{c}\right)$.

\section{Montagem Experimental}

Uma foto do experimento para medida de coeficientes de atrito utilizando recursos computacionais é mostrada na Fig. 1. Um bloco e uma lâmina são colocados em movimento relativo e a força de atrito entre suas superfícies de contato é medida por um sensor de força ligado ao sistema de aquisição de dados. Com esta montagem é possível adquirir, em tempo real, o gráfico da força de atrito em função do tempo e determinar os coeficientes de atrito estático e cinético para diferentes pares de superfícies.

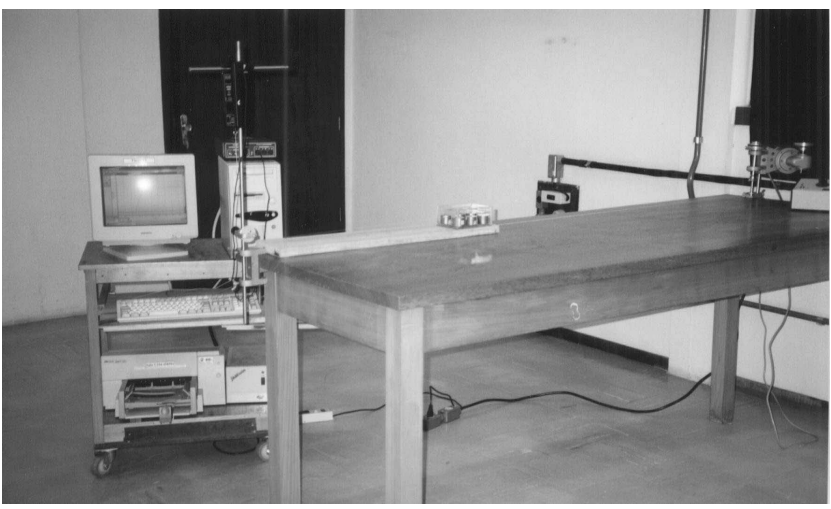

Figura 1. Foto da montagem experimental.

Os diversos materiais utilizados na montagem são mostrados na foto da Fig. 2. Podem-se observar vários blocos e lâminas, correspondendo às diversas superfícies testadas: madeira, acrílico, carpete, lixa, vidro, alumínio e borracha. O bloco consiste em uma caixa dentro da qual podem ser colocadas massas, aumentando assim a força normal do conjunto. A fabricação dos blocos e das superfícies que servem de base não envolvem nenhuma dificuldade especial.

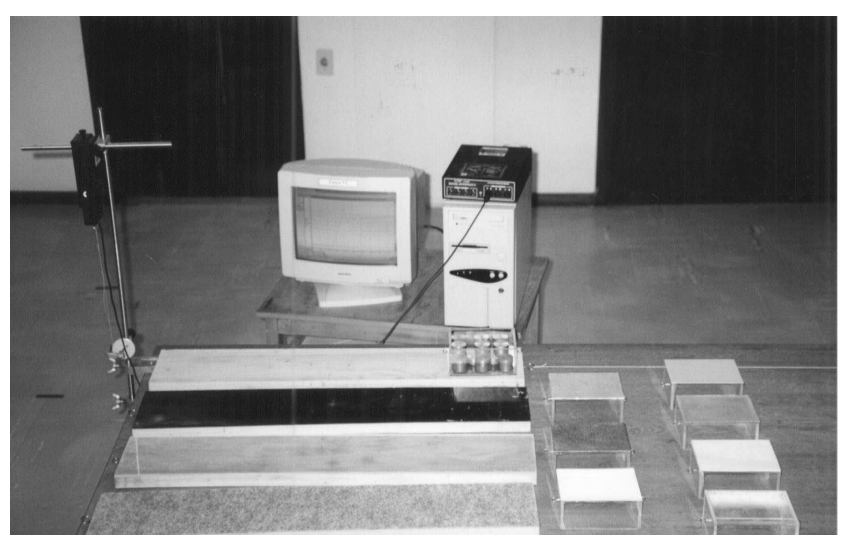

Figura 2. Foto do material utilizado.

O bloco é mantido parado em relação ao laboratório com um auxílio de um fio que passa por uma roldana e está ligado a um sensor de força ${ }^{1}$ posicionado na direção vertical e conectado a um sistema de aquisição de dados. O esquema da montagem pode ser observado na Fig. 3.

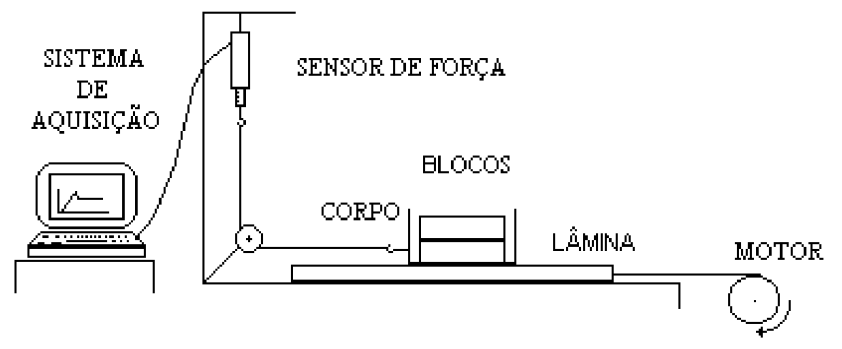

Figura 3. Esquema do experimento.

A lâmina é tracionada por um fio que se enrola no eixo de um motor (a velocidade deste pode ser ajustada). O sensor mede a força resistente, antes de iniciado o movimento e durante este.

\footnotetext{
${ }^{1}$ Usamos um sensor da PASCO, modelo CI 6537. Os dados deste foram tratados em tempo real através do programa "Science Workshop $®$ " do mesmo fabricante.
} 


\section{Resultados}

Na Fig. 4, pode-se observar um gráfico típico, em tempo real, da força de atrito em função do tempo. Este mostra uma reta com inclinação positiva que cresce até um valor máximo, o qual representa a força de atrito estático máximo $\left(f_{e m a ́ x}\right)$ para o par de superfícies considerado (no caso, lâmina de madeira - bloco com base de carpete). Durante essa fase, não existe movimento relativo entre as superfícies e a força de atrito é igual à força aplicada. Após esse pico, a força aplicada é menor, mas suficiente para que a velocidade seja mantida constante. Experimentalmente, a força de atrito tende a se estabilizar em torno de um valor médio: a força de atrito cinético.

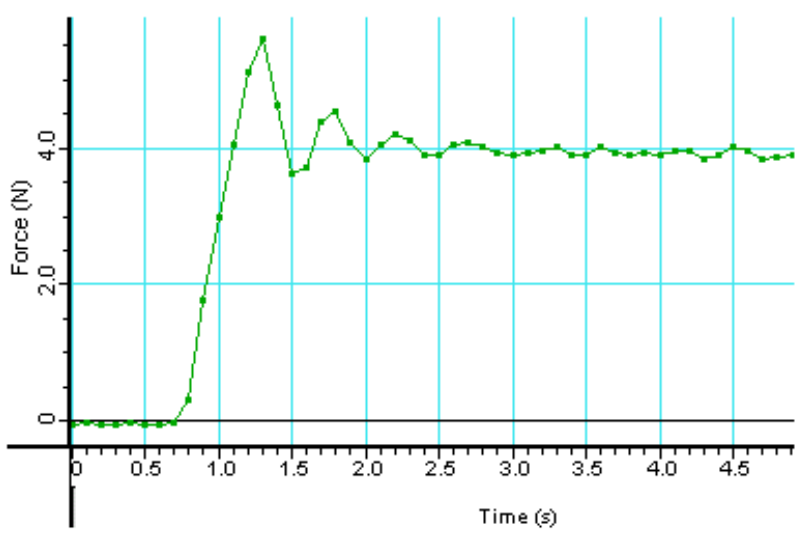

Figura 4. Gráfico da força de atrito em função do tempo, obtido para o par lâmina de madeira - bloco com base de carpete.

Para cada par de superfícies são feitas diversas medidas adicionando-se ou retirando-se blocos da caixa, como mostrado na Fig. 5 para o par lâmina de madeira - bloco com base de borracha. A variação da massa total do bloco altera proporcionalmente o valor da força normal e, de acordo com as equações 1 e 2 , as forças de atrito estático e cinético. $\mathrm{O}$ módulo das forças de atrito é obtido diretamente no gráfico de força em função do tempo para cada valor da força normal.

A partir desses valores, são produzidos gráficos de força de atrito estático ou cinético em função da força normal. Através deles, é possível determinar os coeficientes de atrito para cada par de superfícies. Os dados foram obtidos com a massa variando de $1 \mathrm{~kg}$ a $1,7 \mathrm{~kg}$, de 0,1 em $0,1 \mathrm{~kg}$.

Na Fig. 6, é mostrado um gráfico da força de atrito estático em função da força normal e na Fig. 7, da força de atrito cinético em função da força normal. Uma boa aproximação para os coeficientes de atrito é a inclinação da melhor reta que passa pelos pontos no gráfico. a)

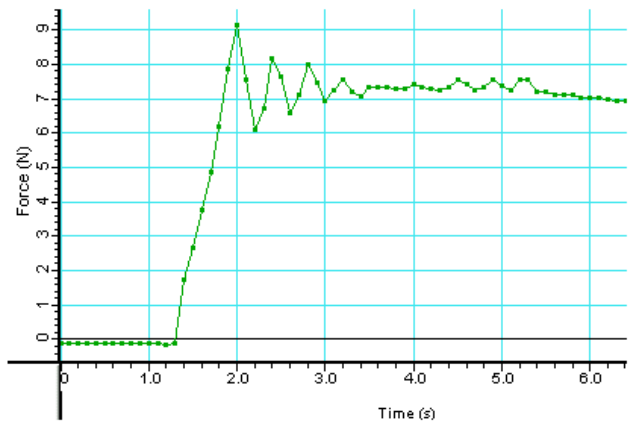

b)

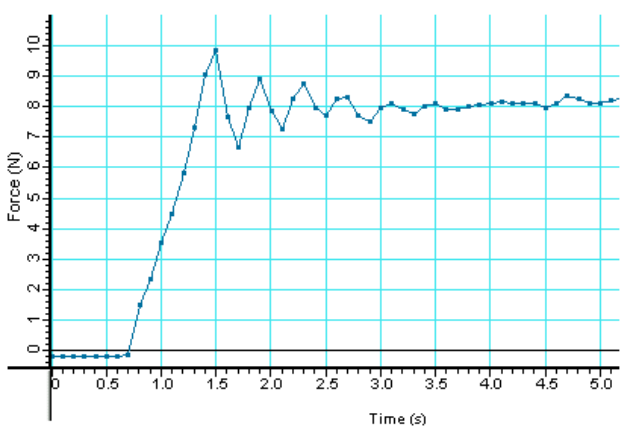

c)

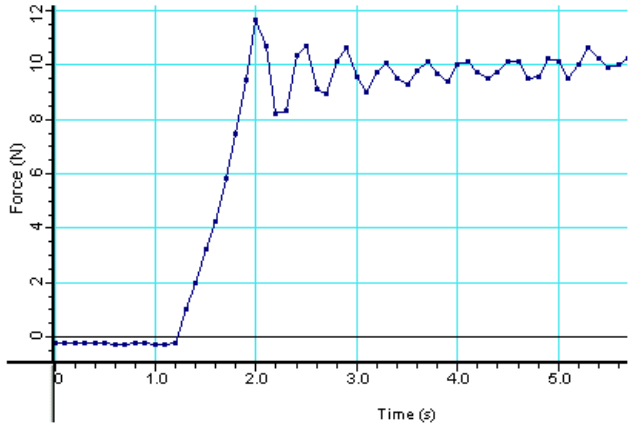

d)

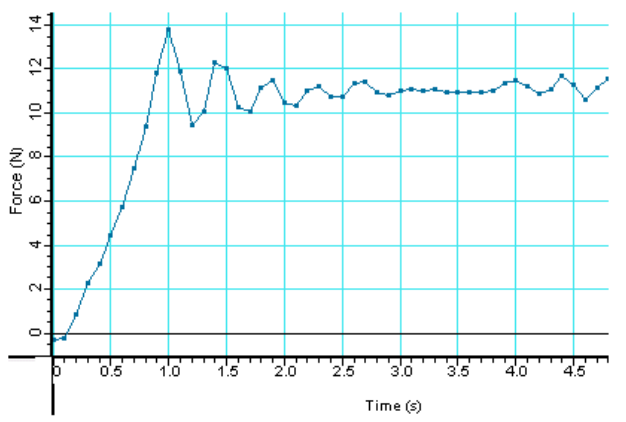

Figura 5. Gráficos da força de atrito em função do tempo, obtido para o par lâmina de madeira - bloco com base de borracha: a) $\mathrm{m}=1,118 \mathrm{Kg}, f_{e}=9,30 \mathrm{~N}$ e $f_{c}=7,28 \mathrm{~N}$; b) $\mathrm{m}$ $=1,218 \mathrm{Kg}, f_{e}=10,40 \mathrm{~N}$ e $\left.f_{c}=8,05 \mathrm{~N} ; \mathrm{c}\right) \mathrm{m}=1,519 \mathrm{Kg}, f_{e}=$ $12,80 \mathrm{~N}$ e $\left.f_{c}=9,64 \mathrm{~N} ; \mathrm{d}\right) \mathrm{m}=1,719 \mathrm{Kg}, F_{e}=13,80 \mathrm{~N}$ e $F_{c}=$ $11,07 \mathrm{~N}$. Para a obtenção da força de atrito cinético não são utilizados os primeiros pontos do gráfico, pois é necessário estabelecer um regime de velocidade constante. É possível notar que, após um certo tempo de movimento, a força de atrito cinético fica razoavelmente estável. 


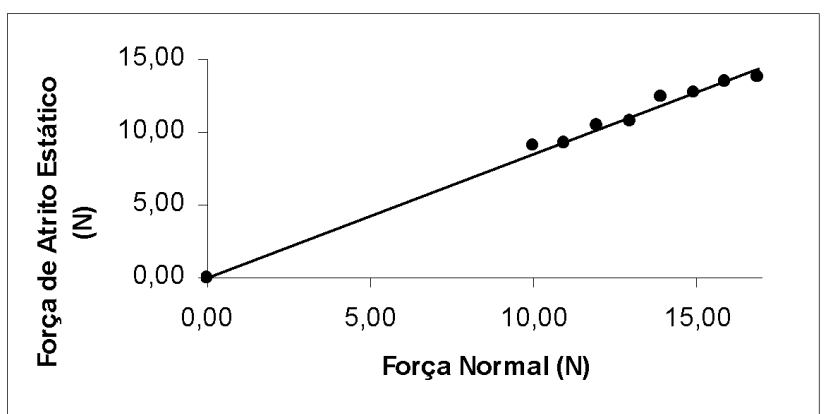

Figura 6. Gráfico da força de atrito estático em função da força normal (madeira - borracha). Os pontos experimentais foram obtidos a partir dos valores máximos dos gráficos, como os da Fig. 5 .

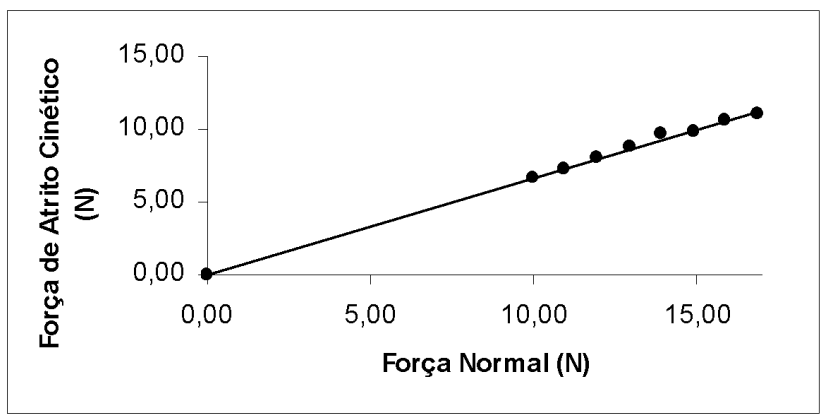

Figura 7. Gráfico da força de atrito cinético em função da força normal (madeira - borracha). Os pontos experimentais foram obtidos a partir dos valores máximos dos gráficos, como os da Fig. 5.

Para o par de superfícies lâmina de madeira - bloco com base de borracha, o valor obtido do coeficiente de atrito estático, a partir da Fig. 6 , é $\mu_{e}=0,84$ e o valor obtido do coeficiente de atrito cinético, a partir da Fig. 7 , é $\mu_{c}=0,66$. Basta uma inspeção visual para constatar que os pontos experimentais se distribuem de forma bastante linear: se o professor desejar quantificar a "qualidade" desta distribuição, ele poderá sugerir aos alunos que calculem o coeficiente de correlação. É claro que os detalhes de tal cálculo superam largamente o nível matemático usual no ensino médio, o que justifica o uso puro e simples dos recursos do programa de computador. O papel do professor será, então, o de dar significado físico a este coeficiente e não de explicar com detalhes como ele é obtido.

\section{Conclusão}

Apesar de os experimentos que envolvem o conceito de atrito não serem novidade, seria excessivamente longo e trabalhoso executar a coleta de dados que gerou os gráficos e as conclusões deste trabalho, sem a aquisição automática de dados: é literalmente impossível obter, num tempo razoável, tais gráficos procedendo de forma "manual". Assim, a introdução da aquisição automática de dados realmente representa um ganho didático, pois em diversos livros de física utilizados no ensino médio [1],[2],[3] aparecem gráficos como este para ilustrar o conceito de força de atrito. Os estudantes têm, então, a oportunidade de entender claramente como eles são gerados e o que significam.

A partir dos gráficos mostrados na Fig. 5, fica evidente que o coeficiente de atrito estático é maior que o coeficiente de atrito cinético. A comprovação disto é obtida com os cálculos das inclinações das retas das Figs. 6 e 7. Os alunos podem obter a melhor reta ajustando "a olho" uma régua transparente sobre os pontos experimentais, ou através da técnica de regressão linear, disponível na maioria dos programas geradores de gráficos. Havendo tempo, o ideal seria executar os dois procedimentos. Esta é uma oportunidade de abandonar de vez o hábito dos alunos de "ligar os pontos" sem perceber a lei física que o gráfico representa.

É possível realizar um tratamento estatístico dos dados mais completo. No entanto, raras são as escolas de ensino médio que propiciam cargas horárias para a disciplina de física que permitam este procedimento. Sendo assim, a abordagem aqui sugerida é vantajosa, especialmente por poder ser executada num tempo razoavelmente curto. Este fator, aliado à motivação que é despertada nos estudantes ao manipularem equipamento informatizado, propicia condições excepcionalmente favoráveis ao ensino e à aprendizagem dos conceitos básicos da física.

Agradecimento: Universidade de Caxias do Sul, FAPERGS.

\section{Referências}

[1] GASPAR, A. Física Mecânica. Vol. 1. Editora: Ática. São Paulo, 2001.

[2] FERRARO, N.G.,TOLEDO, P.A.S. Física Básica. Volume Único. Editora: Atual. São Paulo, 1998.

[3] BONJORNO, J.R., RAMOS, C. M. Física Fundamental - Novo. Volume Único. Editora: FTD. São Paulo, 1999. 